\title{
O HORIZONTE HISTÓRICO DA ARTE INCOMUM
}

\author{
Arley Andriolo
}

O tempo não é uma linha, mas uma rede de intencionalidades. Jean-François Lyotard

RESUMO: 0 objetivo deste texto é apresentar a formação histórica do campo da Arte Incomum no Brasil. Este itinerário de cerca de 100 anos permite ao leitor notar como as proposições psiquiátricas e psicológicas inauguraram o olhar para as obras de nãoarte (obras marginais), representando um horizonte de retenções que dirigiu a recepção das obras. Conclui-se que, embora estas proposições tenham aberto o campo artístico para tais obras, estendem-se para o futuro restringindo o lugar dos criadores marginais.

\section{Raízes da Arte Incomum nas obras dos asilos}

Como se sabe, a idéia de Arte Incomum foi lançada no Brasil em 1981, nos quadros da XVI Bienal de Arte de São Paulo. No entanto, dedicada à criação inventiva de artistas fora do campo profissional, tal idéia deitou suas raízes em décadas anteriores. Foi nos primeiros anos do século $X X$ que um grupo de escritores e artistas possibilitou o interesse para as manifestações até então estranhas ao meio artístico, como as produções de tribos aborígines, as obras populares e, sobretudo, as criações de internos de hospitais psiquiátricos.

No Brasil, esse movimento foi sensível em algumas instituiçõos psiquiátricas das primeiras décadas daquele século. 0 discurso médico adquirira, então, uma importância fundamental 
na organização da vida social e cultural. São famosas as "ligas médicas" dedicando-se aos "problemas sociais", intervindo diretamente em ações públicas. Foi nesse contexto que surgiram as primeiras apreciações de obras plásticas nos asilos, por meio de análises psiquiátricas que oscilaram entre interpretações puramente patológicas - seja nas referências a Max Simon (1876), um dos primeiros a estabelecer relações entre as produções plásticas de asilos com patologias da época, seja a Rogues de Fursac (1905) -, análises formalistas como as de Hans Prinzhorn (1922) e leituras muitíssimo variadas da Psicanálise.

O primeiro a traçar observações sobre as relações entre arte e loucura no Brasil foi Ulysses Pernambucano, quando psiquiatra no Hospital Tamarineira, em Pernambuco, elaborando alguns estudos e conferências sobre o que chamava de "arte nos alienados", no início da década de 1920. As obras por ele examinadas desapareceram, como a maioria das produções de internos de hospitais nesse momento. Conhecemo-las, quando possível, de modo relativo, através de algumas fotografias divulgadas em periódicos médicos. Assim se dá com Tributino dos Santos (1860-?), paciente observado pelo Dr. Pernambucano. Registrado como "preto, casado, natural de Serinhaem, Estado de Pernambuco", trabalhava como "carreiro" e "mestre do açúcar". Era de estatura mediana, musculoso, falador e analfabeto. Diagnosticado como "síndrome paranóide", suas obras datam de 1915, compondo-se basicamente de anéis e medalhas feitos de pedaços de vidros, caquinhos e rolhas de frascos de loção que ele próprio portava e colecionava.

Inspirado pelas palestras de Ulisses Pernambucano, o psiquiatra Sílvio Moura 
elaborou sua tese de conclusão de curso na Faculdade de Medicina do Rio de Janeiro dedicada às Manifestações artísticas nos alienados, apresentada em 1923. Seu texto, o primeiro que se conhece sobre a matéria no Brasil, opta pela descrição de produções coletadas em alguns hospitais brasileiros. Pouco preocupado em analisá-las em profundidade, seu relato oscila entre referências genéricas a Lombroso, Réja e Freud, notando que tais obras despertam o interesse dos "normais" pelo que elas nos trazem de “desrazão”. Nas palavras deMoura (1923, p. 98):

As produções verdadeiramente artísticas não se podem e não se devem confundir com as criações às vezes deslumbrantes de artistas medíocres ou de indivíduos alheios à arte, tocados pelas perturbações mentais, que, no seu começo ativam camartelos, lápis, penas, buris e pincéis, antes do escurecer completo da razão.

Nas décadas de 1910 e 20, o Hospital de Juquery, na cidade de Franco da Rocha, próxima a São Paulo, havia se tornado um centro de estudos psiquiátricos e também psicanalíticos, lugar onde se destacam os trabalhos do Dr. Osório Cesar. Formado anátomo-patologista, desde 1923 trabalhou no Hospital de Juquery onde publicou, em 1925, seu primeiro estudo sobre a produção plástica de "alienados". As idéias psicanalíticas ali apresentadas de modo sintético dominaram suas explicações, tanto das obras de doentes mentais quanto de artistas do meio artístico oficial. Quatro anos depois, em 1929,

Dr. Cesar levou a público seu livro A expressão artística nos alienados (contribuição para 0 estudo dos symbolos na arte). Nesse momento, aprimora seu método de análise, criando um sistema classificatório das obras provenientes 
dos pátios da instituição. Sua interpretação da arte resulta sempre na análise simbólica das imagens. 0 intelectual opera com a noção de inspiração poética em relação ao funcionamento das fantasias infantis e dos sonhos, ou seja, para ele arte é compensação, realização na fantasia daquilo que o real negou (Andriolo, 2003, p. 78).

Entre as manifestações propriamente artísticas, no que diz respeito às obras dos hospitais psiquiátricos, está a exposição organizada por Flávio de Carvalho, talvez o mais radical artista de nosso primeiro modernismo. Trata-se da "Semana dos loucos e das crianças", contando com exposição de obras e palestras no Clube de Artistas Modernos, em 1933. Flávio de Carvalho é considerado o pioneiro, entre os artistas brasileiros, a abrir caminhos para os aspectos "rudes", "instintivos" e "nãointelectualizados" das manifestações artísticas extra-oficiais (Lourenço, 1995, p. 58). Atento ao valor psicológico da obra de arte, o artista afirmou durante a exposição: "Os desenhos dos alienados indicam o caminho para encontrar a gênesis da tortura imensa que sacode a alma do louco".

A historiadora da arte Annateresa Fabris (1981, p. 19) é categórica ao afirmar que tal exposição foi um ataque frontal à estética propugnada pela Escola Nacional de Belas Artes, além de configurar-se também como crítica ao "medíocre gosto da classe média". Conforme a divulgação de época, na revista Rumo (n. 5-6, set. 1933, p. 29), a exposição era composta de:

Desenhos da turma do hospício de Juquery e da garotada de todos os lugares. A arte solta, a imaginação alucinante, sem freio na boca, sem 
algemas, semferraduras. Desabalada. Nas crianças e nos loucos, o mesmo desejo de conseguir todas as coisas sem respeitar convenções ignoradas ou esquecidas. Desprezadas.

\section{Os ateliês hospitalares}

No final da década de 1940 , o olhar médico sobre a arte amplia-se no Brasil. Em setembro de 1946 foi aberta a seção de terapêutica ocupacional do Centro Psiquiátrico Pedro II, no Rio de Janeiro. A direção desta seção ficou a cargo da doutora Nise da Silveira, nascida em Maceió, AL, em 1905, formada em medicina em 1926 na Bahia (faleceu em out. 1999). A Dra. Nise da Silveira introduziu de modo pioneiro naquela instituição um espaço destinado à produção plástica dos internos. As obras oriundas no ateliê eram incorporadas à análise do paciente, contando que as imagens produzidas expressassem informações importantes sobre o seu mundo psíquico, impossível de serem obtidas por meio da linguagem verbal. Todos os freqüentadores da seção eram esquizofrênicos e a produção das obras ali era considerada, sobretudo, conforme duas funções: 1) registrar os conflitos inconscientes do doente; 2) auxiliálo a equilibrar as energias psíquicas.

Depois do encontro com Carl Jung em Zurique, em 1957, a Dra. Nise afirmou sua posição junto à psicologia junguiana, por meio da qual concebe as atividades na terapêutica ocupacional como oportunidade para que as imagens do inconsciente "encontrassem formas de expressão" (Silveira, 1982, p. 13). Pintar, para a Dra. Nise da Silveira, era agir, era "um método de ação adequado para defesa contra a inundação pelos conteúdos do inconsciente". As atividades ocupacionais forneceram-lhe mais consistência que o nível 
verbal poderia oferecer, dentre as quais as artes plásticas parecem o caminho mais notável. Em suas palavras:

Nas imagens pintadas teremos, por assim dizer, auto-retratos dasituaçãopsíquica, imagensmuitas vezes fragmentadas, extravagantes, mas que ficam aprisionadas sobre tela ou papel. Poderemos sempre voltar a estudá-las (Silveira, 1982, p. 115).

A seção de pintura do Hospital de Juquery, por sua vez, foi inaugurada em 1949. Dirigida no seu período inaugural pelo psiquiatra Mário Yahn que dizia estimular a realização de quadros "feitos de imaginação, sem modelo, sem serem copiados e sem sugestão de qualquer pessoa" (Yahn, 1951, p. 26). Para ele, as cópias, a exemplo das pinturas realizadas por um "alcoolista crônico" que com grande habilidade técnica reproduzia Gauguin e Picasso, não possuíam valor "para o estudo da psicologia da arte", uma vez que não expressavam as perturbações próprias do paciente. Ainda assim, o médico considerava "muito difícil estabelecer uma relação entre os fatos essenciais da moléstia, as imagens desenhadas pelos doentes e os fatos normais da sua vida pregressa", assim como o simbolismo pictórico não teria a mesma manifestação livre do simbolismo onírico (p. 28).

Embora não considerasse a existência de uma "arte psicopatológica" propriamente dita, este psiquiatra julgava possível reconhecer o trabalho de um "alienado", o que o aproxima das leituras psicopatológicas dominantes, sobretudo no campo da psiquiatria francesa. A exemplo disso, escreveu Yahn (1951, p. 31):

A produção artística é mais um dos sintomas - e não o essencial - que pode identificar o caráter e a 
personalidadedoindivíduo normal ouanormal. Mas não é obrigatória a sua contribuição para tais fins. Pode, no entanto, trazer maiores esclarecimentos para o último do que para o primeiro.

Nos primeiros anos da década de 1950, Osório Cesar assume a coordenação da seção de pintura do Juquery, época em que divulga uma série de artigos concordantes com suas posições apresentadas nas décadas anteriores, não obstante algumas variações, e realiza várias exposições de obras de pacientes do Juquery. Diferentemente de seu colega Mário Yahn, a interpretação psicopatológica do Dr. Cesar continua a desenvolver-se sobre uma determinada leitura freudiana das obras de seus pacientes.

0 terceiro ateliê psiquiátrico, do qual se tem notícia no Brasil, funcionava na Colônia Juliano Moreira, em Jacarepaguá, então nos arredores da cidade do Rio de Janeiro. Nessa época o hospital estava sob a direção do Dr. Heitor Péres. Ao escrever sobre o tema, este médico afirma sua posição em relação ao valor terapêutico da produção artística entre os pacientes e, em alguns casos, servindo de "instrumento de penetração à intimidade psíquica do enfermo; tal qual um revelador químico que faz surgir corpos novos, a arte - assim usada - nos mostra os aspectos incógnitos da enfermidade" (Péres, 1950, p. 1).

A produção plástica nas oficinas da Colônia Juliano Moreira, ao contrário das instituições anteriormente citadas, era dirigida conforme a solicitação de cada caso em sua especificidade. 0 paciente Hyacinto Neves, por exemplo, era convidado a pintar ao ar livre:

Neste enfermo a orientação arteterápica 
mais acertada, tem sido a de levá-lo a copiar d'aprés nature, estimulando melhor contato com o meio, evitando a composição espontânea que the acentua a dissociação e, portanto, o desajustamento psíquico (Péres, 1950, p. 6).

De maneira geral, as interpretações propostas para as obras surgidas nos hospitais psiquiátricos desse momento revelam a exterioridade do conhecimento que não as admitia como valor em si mesmas, uma vez que a produção de um interno, considerada como documento clínico, completava o diagnóstico psiquiátrico. Além disso, tais criadores eram membros de uma classe social muito distinta daquela de onde seus intérpretes falavam, o que aprofundava a incompreensão das visões representadas nas obras.

Mesmo no modelo psicanalítico proposto por Osório Cesar, que não era senão mais uma leitura de Freud adaptada à realidade hospitalar, a investigação que partia do objeto acabava por fechar-se em categorias psicopatológicas. $\mathrm{Na}$ contracorrente, Nise da Silveira pode ser vista sob um duplo aspecto: primeiro, como exceção, porque vislumbrava a interioridade desses processos criativos; segundo, porque afirmava não lidar com obras de arte e sim com imagens do inconsciente.

\section{A obra dos internos em exposição}

O desenvolvimento dos ateliês assinalado no final dos anos 40 estimulou o campo médico brasileiro não apenas a pensar as questões suscitadas por essa produção, mas também a realizar práticas externas aos muros das instituições. Dando, assim, oportunidade ao público leigo de tomar contato com essas 
estranhas criações.

Foram duas as exposições iniciais das obras provenientes do ateliê dirigido por Nise da Silveira, uma em fevereiro de 1947, no Ministério da Educação, outra em outubro de 1949, no Museu de Arte Moderna de São Paulo, então dirigido por Leon Degand, intitulada "9 Artistas de Engenho de Dentro” (Silveira, 1994, p.15).

No ano de 1948, concretizara-se no Hospital de Juquery a idéia de se organizar uma exposição com as obras coletadas pelo doutor Osório Cesar nos pátios da instituição. Intitulada "I Exposição de Arte do Hospital do Juquery", a mostra foi organizada pelo próprio psiquiatra no Museu de Arte de São Paulo, entre 19 de outubro e 19 de dezembro. Como nas outras exposições, realizouse paralelamente um ciclo de conferências. Na década de 50 , este médico foi responsável por uma série de exposições dessa natureza, seja no Museu de Arte de São Paulo, seja no Clube dos Artistas e Amigos da Arte, seja em instituições pelo interior do Estado de São Paulo.

A “Primeira exposição de pintura, arte feminina aplicada da Colônia Juliano Moreira" ocorreu em maio de 1950, reunindo parte das obras então produzidas no trabalho terapêutico. Através do breve catálogo em circulação no evento, pode-se ler algumas notícias da "personalidade e a obra dos pintores", bem como informações sintéticas sobre a nomenclatura médica, permitindo ao "leitor-leigo" uma compreensão maior das obras.

Nesse mesmo ano, durante o primeiro Congresso Mundial de Psiquiatria, em Paris (setembro de 1950), foi organizada no Centro Psiquiátrico Sainte-Anne uma exposição de obras 
de arte produzidas por doentes mentais. O Brasil foi representado na mostra com quatro coleções, num total de 57 casos e 395 obras, provenientes das três instituições psiquiátricas observadas no item anterior (Volmat, 1956).

A leitura dos textos de Robert Volmat e a observação das obras reproduzidas nos dão alguma indicação dos autores que mais se destacaram. Dos freqüentadores do ateliê de Nise da Silveira é relevante o papel de Raphael. Da coleção de Mário Yahn aparece Rubens Garcia, cuja técnica de retratista parece ter atraído muita atenção, promovendo mesmo a doação de parte dessa coleção para a Société International de Psychopathologie de l'Expression, organizada no Centro Hospitalar Sainte-Anne por Volmat. Das obras enviadas por Heitor Péres destacam-se as de Bragança, num óleo sobre tela intitulado La fécondité chinoise, no qual uma mulher oriental com os dois cotovelos sobre a mesa e as mãos apoiando a cabeça vomita sobre um prato pequenas figuras humanas. Finalmente, entre as peças concedidas por Osório Cesar, são relevantes os desenhos simbólicos de Albino Braz.

Das coleções citadas, aquela organizada por Nise da Silveira foi a única transformada na época em um museu permanentemente aberto à visitação pública. Todas as outras esperariam, enquanto eram desfalcadas, a criação de museus próprios nos anos 80 . Inaugurado em 20 de maio de 1952, cinco anos depois, parte de suas obras foi levada pela Dra. Nise da Silveira a Zurique para exibição no II Congresso Internacional de Psiquiatria, tendo sido a exposição brasileira inaugurada por Carl G. Jung.

A sistemática de catalogação empregada segue o modelo do Bild Archiv do Instituto C. G. 
Jung de Zurique. Nas palavras da Dra. Nise da Silveira (1994, p. 23), o funcionamento do Museu segue as seguintes características peculiares:

Recebe todos os dias material novo, produzido no atelier de pintura. Este material é examinado, selecionadas as pinturas de interesse mais imediato e arquivadas as demais, segundo autores e datas, para estudos posteriores. Segue-se a organização, em álbuns, de seqüências de imagens que permitem acompanhar o desdobramento do processo psicótico em casos individuais, bem como a reunião de imagens referentes ao mesmo tema, produzidas por autores diversos. Procedese a pesquisa de paralelos históricos para essas imagens, quando são encontradas trilhas nesse sentido.

Nos anos 70, quando o Brasil vivia sob o regime militar, o Museu de Imagens do Inconsciente beirou sua extinção, mas sobreviveu, dado o prestígio da Dra. Nise e do apoio de importantes intelectuais. No final dessa década, após a aposentadoria compulsória da doutora, foi lançado em nível nacional o belo catálogo dedicado ao acervo do museu. Dos autores cujas obras compõem o acervo, além do citado Raphael, é necessário marcar a significação de Fernando Diniz, Emygdio de Barros, Adelina, Carlos, entre outros.

Não obstante sua clara posição, no interior de um hospital, o Museu de Imagens do Inconsciente promoveu a abertura permanente da criação dos internos às leituras propriamente estéticas dentro de um universo cerrado pelo olhar psiquiátrico. Não é, assim, paradoxal a dedicação que Mário Pedrosa ensejou sobre esses criadores.

\section{Uma possibilidade de olhar estético}


A intervenção do pensamento de Mário Pedrosa foi determinante no valor das obras que pipocavam nos hospitais psiquiátricos. A Psicologia da Forma, como lembra Otília Arantes (1996, p. 33), aparece nesse crítico com o intuito de "determinar os fundamentos da universalidade da experiência estética", os quais desfazem o conflito subjetividade versus objetividade, forma versus expressão, "ao fornecer uma explicação científica (e mesmo materialista) para a percepção estética". Como dizia Mário Pedrosa (1996, p. 176):

0 poder de comando que exerce um quadro sobre nós vem de dentro de si mesmo. Todo o segredo de sua força atuante, da magia que exerce sobre nós, dessa faculdade única que é a sua de nos despertar emoção, reside em sua estrutura formal, na sua Gestalt.

Assim, para Pedrosa interessava a existência própria do objeto de arte, bem como suas qualidades formais. Segundo esse crítico, a psicologia atuando de modo tradicional entre o artista e o espectador deixaria de fora a obra. Citando Koffka, lembra que uma psicologia da obra seria "a terceira tarefa do psicólogo" (Pedrosa, 1996, p. 152). Diante da produção de internos de hospitais psiquiátricos, é notável a referência do livro de Hans Prinzhorn para as formulações do crítico brasileiro. Nessa perspectiva, o pensamento de Pedrosa tratase do principal movimento contrário à corrente das interpretações psicopatológicas, ainda que colhendo seu material para reflexão junto a asilos psiquiátricos, propõe um debate estritamente estético.

No ano de 1947, o crítico realizou a conferência de encerramento da primeira exposição 
organizada pelo Centro Psiquiátrico Nacional, intitulando-a "Arte, necessidade vital". E, em 1950, formula a designação que acompanhou suas análises de obras de arte surgidas em condições não profissionais. Num artigo para o Correio da Manhã (10 jan. 1950) afirma tratarem-se de uma "Arte Virgem". Naquele momento organizava a exposição "Cinco Artistas de Engenho de Dentro", na Câmara de Vereadores do Rio de Janeiro, junto de Nise da Silveira e Almir Mavignier.

O processo emocional e dinâmico que pode ser estudado em laboratórios de psicologia é encontrado livremente nos "criadores virgens", como nos "verdadeiros artistas", escreveu Pedrosa. Propunha que "os doentes mentais não precisam passar por experimentações de laboratório para perceber as coisas, as formas, sem indiferença, ou fisionomicamente". Essas pessoas vêem tudo simultaneamente por dentro e por fora, por isso são conduzidas por uma atitude estética, como observou o crítico em 1951:

Movidas pelo mesmo impulso é que milhares de pessoas humildes - empregados públicos, porteiros, sapateiros, jardineiros - se dão anonimamente ao passatempo domingueiro de fazer objetos novos, inéditos, de pintar, esculpir, pelo simples prazer de criar. São criadores virgens. São homens que até hoje não conseguem contemplar o mundo sem estremecer, comovidos (Pedrosa, 1996, p. 195).

Como se vê, embora manifestamente lidando com as obras oriundas do Centro Psiquiátrico Pedro II, o crítico não utiliza categorias psicopatológicas. A proposição sobre o valor da arte das pessoas economicamente pobres e marginais vinculou-o momentaneamente às idéias estéticas de Jean Dubuffet. Pedrosa dedicou uma extensa nota de 
rodapé mencionando a fundação da Compagnie de l'Art Brut, ocorrida no ano de 1948. Embora não se detenha na formulação acerca de uma Arte Bruta, Pedrosa é provavelmente o primeiro a citar esta noção no Brasil. No entanto, a valorização da Arte Virgem propugnada por Pedrosa, não está, como em Dubuffet, associada à crítica radical da arte oficial. Como se sabe, Mário Pedrosa nunca ignorou as diferenças entre as manifestações virgens e arte culta (Arantes, 1996, p. 25); interessava-lhe, no entanto, a origem da criação, algo como a essência do fazer artístico.

Nos processos inconscientes, o crítico localiza o surgimento do fenômeno de constâncias, numa tendência à repetição de formas simétricas ou concêntricas (Pedrosa, 1996, p. 214). Diante de tais análises, torna-se possível compreender por que o diálogo entre Mário Pedrosa (formalista) e Nise da Silveira (junguiana) foi tão profícuo.

\section{Arte Incomum: recepção e alteridade}

À exceção das atividades sustentadas pelo Museu de Imagens do Inconsciente, que também sofreu as agruras do domínio político dos militares, as décadas de 1960 e 1970 marcam o silêncio das produções plásticas dos hospitais psiquiátricos. Coleções, como a do Hospital de Juquery, foram enfiadas nos porões ou simplesmente disseminadas, enquanto os muros das instituições fechavam-se novamente. Somente no início dos anos 80 ver-se-ia tais produções novamente expostas ao público.

É nesse momento que aparece a nomenclatura Arte Incomum, utilizada no Brasil, em 1981, para obras estranhas ao meio artístico oficial, aquilo que no correr da história figurava como não-arte, 
arte marginal, arte dos loucos... O termo surgiu para denominar um módulo da XVI Bienal de Arte de São Paulo ${ }^{1}$ realizado sob a dupla curadoria de Victor Musgrave (para o acervo internacional) e Annateresa Fabris (para as obras nacionais). Ali estavam reunidas obras provenientes do Museu de Imagens do Inconsciente, do que sobrara da coleção de Osório Cesar, além de criadores inventivos oriundos de classes populares, como G.T.O., Poteiro, Eli Heil, entre outros.

Nas palavras do curador da Bienal, Walter Zanini (1981, p. 7), a Arte Incomum pode ser definida como:

múltiplas manifestações individuais da espontaneidade de invenção não-redutíveis a princípios culturais estabelecidos. Por outras palavras, ainda, a produção de seus autores é independente dos padrões habitualmente reconhecidos na síndrome da artisticidade, opondo-se a espécie marginal de sua mensagem às características reguladoras da atividade profissional.

Annateresa Fabris (1981) intitulou seu texto para o catálogo de "Cosmogonias Outras", numa referência à necessidade de particularizar

( $\left.{ }^{1}\right)$ Têm-se notícias no Brasil da organização de uma galeria paulistana denominada Art Brut, da qual participavam artistas profissionais descontentes com o meio oficial. Foi também esse o momento da "descoberta" do criador Arthur Bispo do Rosario, interno da Colônia Juliano Moreira que se tornou o protótipo de artista marginal no Brasil. Nessa mesma instituição foi criado o Museu Nise da Silveira (atualmente denominado Bispo do Rosario), com o intuito de preservar as obras produzidas no interior da instituição. No Hospital de Juquery, desenvolveu-se um trabalho de resgate das coleções de Osório Cesar e Mário Yahn, coordenado por Heloísa Ferraz (1998), aberto ao público em 1985 e denominado Museu Osório Cesar. 
cada um dos criadores como um universo próprio, contrária, neste caso, às classificações tradicionais da história da arte. Fabris pensa a exposição relembrando Flávio de Carvalho, o artista brasileiro que em 1933 organizou a mostra pioneira de "crianças e loucos", e Jean Dubuffet que radicalizou mais, anulando a distinção entre o “louco" e o “são”, em sua crítica à idéia de arte "anormal", interessando-se pela obra pessoal.

Os anos que se seguiram à mostra de Arte Incomum revelaram 0 aumento de interesse para as obras não oficiais. Além de ser uma ressonância à exposição de 1981, acompanhavase no Brasil um movimento notável no cenário europeu, a exemplo da criação de coleções como a Fabuloserie (Dicy, 1983), L'Aracine (Neuillysur-Marne, 1982), o Art Cru Museum (Monteton, 1984), os Outsiders Archives (Londres, 1981) e a associação Art en Marge (Bruxelas, 1985).

Enfim, a exposição de Arte Incomum de 1981 marca também o início dos estudos de recepção em exposições de arte no Brasil. Trata-se da tese de João Augusto Frayze-Pereira, defendida em 1987 no Instituto de Psicologia da Universidade de São Paulo e publicada em 1995 com o título de Olho d'água: arte e loucura em exposição. Tal obra representa uma nova visada sobre o campo da Arte Incomum no Brasil, num sentido que historicamente estende o olhar de Mário Pedrosa e Dubuffet, ainda que segundo métodos distintos.

Este psicanalista constatou que, de maneira geral, o acolhimento das manifestações incomuns foi positivo, ainda que declaradamente com estranheza e espanto. Despertou no público a necessidade de repensar a si mesmo e o mundo, sendo assim uma arte que "questiona o homem", 
de onde despertam os temas da "vida", do "além da vida", da "liberdade", "inovação-mistérioorigem", "identidade-alteridade".

Como notou Frayze-Pereira (1995, p. 75), as questões suscitadas:

tiveram como ponto de apoio a percepção da vitalidade das cores, do uso de materiais com efeitos inesperados (ex. lápis, lâmpadas, cacos de ladrilho), da maneira do desenho cuja pintura nem sempre é bem acabada, das composições a partir de motivos inusitados, porém vividos, dos mitos e estórias que cada obra supostamente encarna, da alma e da vida do criador que cada um expressa.

$\mathrm{Na}$ interpretação de Merleau-Ponty sobre a pintura, essencial às proposições de João FrayzePereira (1995, p. 136), o inacabamento essencial de uma obra a ser vista (que é do próprio visível) pede ao espectador retomar o gesto que a criou, ou seja, põe-no em contato com o outro. 0 paradoxo da visão orienta, então, o espectador para a questão da identidade e da diferença, ou melhor, a identidade na diferença.

O olhar do público nos faz rever aquilo que anteriormente designamos como um conhecimento de exterioridade, ou seja, fundado tão-somente num olhar de sobrevôo, como diria Merleau-Ponty. Os entrevistados de Frayze, paradoxalmente porque guiados por sua "fé perceptiva", não se obrigam aos modelos psicopatológicos de interpretação, buscando a interioridade do processo criativo, de modo muitas vezes radical. Por essa via revelam os três tópicos apontados por Frayze-Pereira (1995, p. 139): 1) a tematização da Vida intrinsecamente 
ligada à questão da Liberdade; 2) a aproximação do espectador quanto ao absolutamente Outro que transforma o Eu que observa numa questão; 3) a retomada de uma tradição mais velha do que a própria arte (a Percepção) que remete o visitante, através do estranhamento e do temor nele suscitados, à questão do Mistério da Origem.

\section{O horizonte de retenções da Arte Incomum}

Em 1989, o termo Arte Incomum figura no compêndio de artes visuais elaborado por Frederico Morais, dando-lhe o devido crédito como categoria artística; uma tradução do francês Art Brut, ocupando o "espaço impreciso entre a arte popular e a arte erudita" (Morais, 1989, p. 80 ). No entanto, observando em retrospectiva os eventos que se seguiram à exposição de 1981, vemos que este conceito não se sustentou por muito tempo na intelectualidade brasileira. Ao contrário do campo formado em torno dos naïfs ${ }^{2}$, nos escritos sobre artes, a utilização do termo Arte Incomum rareia.

Os motivos para a pouca utilização da designação de Arte Incomum no Brasil podem ser encontrados em sua própria história, tal como a resumimos aqui, ou seja, em seu horizonte de retenções. Este horizonte está definido pela concepção fenomenológica de história,

(2) Há uma associação importante, do ponto de vista da história da arte, entre o que se designa "ingênuos", a produção plástica dos hospitais psiquiátricos e o conjunto da "arte marginal", a qual, porém, face à sua extensão, não será abordada aqui. A Arte Incomum colocou esta problemática lançando Eli Heil, G.T.O. e Poteiro no centro do debate. Ver a esse respeito Andriolo (2004, pp. 156-161). 
notadamente em Jean-François Lyotard (1986, p. 90), concebendo o tempo não como uma linha, mas como uma "rede de intencionalidades". Quando foi lançada na cultura brasileira, a idéia de Arte Incomum encontrou em sua historicidade a força do discurso psicopatológico (Andriolo, 2004, p. 162).

O principal exemplo que poderíamos fornecer desta nossa afirmação é a grande exposição comemorativa da Mostra do Redescobrimento, realizada na Bienal de São Paulo, em 2000.

O termo Arte Incomum simplesmente não foi utilizado nesta mostra que tinha como objetivo apresentar um resumo da produção da história da arte brasileira. Muitas das obras expostas em 1981 como incomuns foram deslocadas para o campo da "arte popular" (ex. Poteiro e G.T.O.), engrossando deveras o catálogo desse módulo e o que seria incomum reuniu apenas obras provenientes de hospitais psiquiátricos ${ }^{3}$.

Todos que conhecem a idéia de Art Brut, da qual, em primeira instância, deriva a noção de Arte Incomum, sabem das críticas de Dubuffet acerca da "arte psicopatológica" e da "arteterapia”. O pensador era radicalmente contra a vinculação da sua coleção com a idéia ocidental de loucura (p. ex. Dubuffet, 1999, p. 92 e 111). Sabe-se também que apenas $40 \%$ das obras da Collection de l'Art Brut de Lausanne são provenientes de coleções psiquiátricas, os outros $60 \%$ não têm nenhuma relação com esse meio.

${ }^{3}$ ) Convém lembrar que todos os museus criados no Brasil para as coleções anteriormente citadas são ligados a instituições asilares. 
Na referida exposição de 2000, no entanto, circunscreveu-se o lugar das obras incomuns, daquilo que não era arte oficial, junto à produção psiquiátrica. Em particular na leitura desenvolvida por Nise da Silveira, como se supõe pelo título do módulo: "Imagens do Inconsciente".

Como dizíamos, além de se fechar o campo sobre aquilo que se entendeu como psiquiátrico, as obras que não se enquadravam neste rótulo foram deslocadas para o campo da arte popular. Mas arte popularé aquele tipo de produção plástica coletiva, circunscrita por regras tradicionais e "feita a fim de satisfazer necessidades do grupo social, ou ornar objeto útil”, como definiu Mário Barata (1950, p. 31). Ora, criadores como Antônio Poteiro, Geraldo Teles de Oliveira, José Valentim Rosa, entre outros, em essência, desprendem-se do universo popular. Por isso, já em 1978, Lelia Frota os designava como "artistas liminares".

Estes exemplos, ou outros que poderíamos aventar, são tão estranhos à arte popular quanto o são às categorias psiquiátricas, verdadeiramente representantes de uma outra categoria artística, que Dubuffet chamou de Art Brut e que os brasileiros ainda relutam em aceitar como tal, mas cuja existência é marcante. 0 problema da existência do campo da Arte Incomum, ou outro nome que lhe dermos, não é o que importa e pode começar a ser observado a partir da linguagem estabelecida entre nós e tais objetos, mesmo que eles sejam, como muitos o são, produzidos para seus próprios autores.

\section{Referências:}

ANDRIOLO, Arley. Traços primitivos: histórias do 
outro lado da arte no século XX. São Paulo, 2004, 220 p. Tese (Doutorado), Instituto de Psicologia da Universidade de São Paulo.

ANDRIOLO, A. A psicologia da arte no olhar de Osório Cesar: leituras e escritos. Psicologia Ciência e Profissão, n. 23 (4), 2003, pp. 74-81. ARANTES, O. B. F. Prefácio: Mário Pedrosa, um capítulo brasileiro da teoria da abstração. In: PEDROSA, M. Forma e percepção estética. São Paulo: Edusp, 1996, pp. 14-38.

Arte Incomum. XVI Bienal de São Paulo, 16 out. a 20 dez. 1981. Curadoria Geral Walter Zanini; Curador da Exposição Internacional de Arte Incomum Victor Musgrave; Curador da Exposição Nacional de Arte Incomum Annateresa Fabris.

BARATA, M. Conceito e metodologia das artes populares. Separata de Cultura, n. 3, Rio de Janeiro, Ministério da Educação e Saúde, Serviço de Documentação, pp. 27-46, 1950.

CESAR, O. A arte primitiva nos alienados: manifestação esculptórica com caracter symbolico feiticista num caso de syndroma paranóide. Memórias do Hospital de Juquery, São Paulo, ano 2, n. 2, pp. 111-125, 1925.

CESAR, O. A expressão artística nos alienados. (contribuição para o estudo dos symbolos na arte). São Paulo: Officinas Graphicas do Hospital de Juquery, 1929.

DUBUFFET, J. L'homme du commun à l'ouvrage. Paris: Gallimard, 1999.

FABRIS, A. Cosmogonias outras. In: Arte Incomum. XVI Bienal de São Paulo, 16 out. a 20 dez. 1981, pp. 19-25.

FERRAZ, H. C. Arte e loucura: limites do imprevisível. São Paulo: Lemos, 1998.

FRAYZE-PEREIRA, J. A. Olho D'Água: arte e loucura em exposição. São Paulo: Escuta, 1995. FROTA, L. C. Mitopoética de 9 artistas brasileiros. Rio de Janeiro: FUNARTE, 1978.

LOURENÇO, M. C. Operários da modernidade. 
São Paulo: Hucitec/Edusp, 1995.

LYOTARD, Jean-François. A fenomenologia. Lisboa: Edições 70, 1986.

MORAIS, F. Panorama das artes plásticas, séculos XIX e XX. São Paulo: Itaú Cultural, 1989.

Mostra do Redescobrimento. Nelson Aguilar (org.) Fundação Bienal, Catálogo de Exposição. São Paulo: Associação Brasil 500 Anos Artes Visuais, 2000.

MOURA, S. B. A. Manifestações artísticas nos alienados. Tese apresentada à Fac. de Medicina do Rio de Janeiro, 10 nov. 1923. Rio de Janeiro: Off. Graph. do “João Pestana”, 1923.

PEDROSA, M. Forma e percepção estética. São Paulo: Edusp, 1996.

PERÉS, H. Primeira Exposição de Pintura, Arte feminina aplicada da Colônia Juliano Moreira [Catálogo de Exposição]. Rio de Janeiro, maio, 1950.

SILVEIRA, N. Imagens do inconsciente. 2 ed. Rio de Janeiro: Alhambra, 1982.

SILVEIRA, N. O Museu de Imagens do Inconsciente. In: FUNARTE/IBAC. Coordenação de Artes Visuais. Museu de Imagens do Inconsciente. 2 ed. Rio de Janeiro: FUNARTE/Ed. UFRJ, 1994, pp. 13-29. (edição original 1980)

VOLMAT, R. L'art psychopathologique. Paris: PUF, 1956.

YAHN, M. Exposição de arte psicopatológica no I Congresso Internacional de Psiquiatria de Paris. Arquivos do Departamento de Assistência a Psicopatas do Estado de São Paulo, Franco da Rocha, vol. XVI, jan-dez., pp. 23-32, 1951.

ZANINI, W. A Bienal e os artistas incomuns. In: Arte Incomum. XVI Bienal de São Paulo, 16 out. a 20 dez. 1981, pp. 7-8. 